\title{
Potentiometric Method for Evaluating the Oxidant/Antioxidant Activity of Seminal and Follicular Fluids and Clinical Significance of this Parameter for Human Reproductive Function
}

\author{
Kh.Z. Brainina ${ }^{*}, 1,2$, E.L. Gerasimova ${ }^{2}$, D.P. Varzakova ${ }^{1}$, S.L. Balezin ${ }^{3}$, I.G. Portnov ${ }^{3}$, \\ V.A. Makutina ${ }^{3}$ and E.V. Tyrchaninova ${ }^{3}$ \\ ${ }^{I}$ Urals State University of Economics, Department of Physics and Chemistry, Ekaterinburg, Russia \\ ${ }^{2}$ Ural Federal University named after the first President of Russia B.N.Yeltsin, Ekaterinburg, Russia \\ ${ }^{3}$ The Family Medicine Centre, Ekaterinburg, Russia
}

\begin{abstract}
Potentiometric method based on the sharp change of electrode potential for the ferricyanide/ferrocyanide mediator system after addition of the seminal or follicular fluid sample into the measuring electrochemical cell has been developed to enable the easy assessment of the oxidant/antioxidant status of these kind of biological fluids. Platinum screen printed electrode has been used as an indicator. Essential advantage of the proposed method is simultaneous use of the both forms of the ferricyanide/ferrocyanide mediator system (oxidized and reduced ones) that allows estimating oxidant and antioxidant components of the seminal or follicular fluids samples which were obtained, respectively, from 99 male and 27 female subjects. Oxidant activity of seminal fluids has been observed in pathology conditions of reproductive system of male studied subjects and related with possible male infertility symptoms.
\end{abstract}

Keywords: Male infertility, ferricyanide/ferrocyanide system, oxidant/antioxidant activity, potentiometry, seminal and follicular liquids.

\section{INTRODUCTION}

Reactive oxygen species (ROS) play an important role in male sperm functioning. Under physiological conditions, ROS are essential for capacitation reaction, acrosomal reaction and fertilization processes in general. Overproduction of ROS is important in pathogenesis of male infertility along with the development of oxidative stress. It should be emphasized that sperm cells are most sensitive to ROS, as compared with other cells in the body due to high concentration of polyunsaturated fatty acids in plasma membranes and low concentration of antioxidant enzymes in cytoplasm [1]. There are many factors that may have negative impact on male fertility. One of the factors is hyperproduction of ROS. The reasons for hyperproduction of ROS may vary with age, lifestyle, infectious and inflammatory diseases of the reproductive organs, etc. [2]. In seminal fluid ROS are produced by leukocytes as well as sperm (mis-differentiation of cells during the stages of spermatogenesis). With higher concentration of leukocytes in seminal fluid generating more ROS than sperm, leukocytes become the dominant source of ROS.

The presence of excessive ROS has a toxic effect on sperm cells, both on the quality and functional ability of sperm [3]. Thus, the presence of oxidative stress may lead to idiopathic forms of male sterility. Moreover, excessive ROS can cause induced apoptosis of sperm, and damage their DNA [4]. Breakages in DNA are a key indicator of cell death [4].

*Address correspondence to this author at the Urals State University of Economics, 620144 Ekaterinburg, 8th of March St., Bld.62, Russia; Tel: +73432572415; Fax:+73432572415; E-mail: baz@usue.ru
ROS also play a dual role in the female reproductive system [5]. The impact of ROS on the female sexual function needs thorough studies. It is known that low concentration of ROS can predict successful fertilization. The excess of ROS, affecting the membrane of gametes, damages its fluidity, initiates apoptosis in a cell and can cause infertility [6]. Particular attention is paid to the ability of peritoneal macrophages to generate ROS, which creates constantly high levels of ROS in the peritoneal fluid and violates lipid peroxidation oxidation (LPO). These processes damage healthy cells and tissues, disturbing the fertilization process [5]. Miscarriage is also accompanied by lower concentration of antioxidants [7].

Thus, the in-depth analysis of the reasons for male and female infertility in each case in order to select pathogenetically justified treatment is still immediate challenge. The dual role of ROS in the body and the consequent need to maintain a balance between the generation of ROS and oxidant/antioxidant activity (OA/AOA) of seminal and follicular fluids requires monitoring of this last mentioned parameter.

There are several methods for determining the oxidant/antioxidant status of semen. It is worth mentioning fluorescent methods, in particular, a method for determining hydrogen peroxide described in the World Health Organization laboratory manual for examination and processing of human semen [8].

The methods for determining superoxide anions describe use of nitroblue tetrazolium and ferricytochrome $c$ reduction [9].

Information about concentration of ROS can also be obtained using the reaction with dichlorofluoresceine-diacetate (DCFH-DA) or dihydroethidine (DHE), accompanied by the 
appearance of fluorescence [10]. Direct universal method for detecting ROS, based on a study of electron spin resonance, is known [11] but this method is not widely used in medicine because of the use of expensive and cumbersome technique.

Immunoenzyme methods for determining indirect indicators of seminal oxidative stress such as myeloperoxidase enzyme or inflammatory cytokines-chemokines which are activated when the generation of ROS is increased were also described [12-13]. Indirect indicators of seminal oxidative stress include the level of lipid peroxidation, determined by optical methods after the reaction with thiobarbituric acid [14]. The method provides information about the changes that have already occurred but does not characterize the state of the system in-situ. The method is not specific, determination is interfered with some nucleic and amino acids.

The most reliable marker of sperm apoptosis is DNA fragmentation that quantitatively can be determined by various methods $[15,16]$, for example, by the luminescence method where luminescence intensity is proportional to the number of labeled nucleotides built in the DNA breaks by terminal deoxynucleotidyl transferase dUTP nick end labeling assai (TUNEL) or by fluorescence of acridine orange which depends on whether it is associated with single-stranded or doublestranded DNA (sperm chromatin structure assay, SCSA). However, DNA damage does not necessarily indicate the presence of oxidative stress in the body.

All described methods for determining concentration of ROS quite adequately reflect the state of the sperm oxidant system, but do not present any information about the state of the antioxidant system.

To assess the state of the antioxidant system the methods for determining the activity of enzymes [17, 18], concentration of either certain substances $[19,20]$, or the amount of substances that exhibit antioxidant activity as an integral parameter [21, 22] have been used.

Antioxidant enzymes such as catalase, superoxide dismutase and glutathione peroxidase create the antioxidant enzyme system to protect sperm from ROS [17, 18], but the determination of enzymatic antioxidants do not give a complete picture of the antioxidant defense system of sperm. The same disadvantages are demonstrated by chromatographic methods for determining individual non-enzymatic antioxidants [20], such as $\alpha$-tocopherol, $\beta$-carotene, lycopene, and ascorbic acid.

In seminal plasma, ascorbate, urates, and thiols are the major antioxidants while only traces of $\alpha$-tocopherol were detected in sperm from any group of males. Neither $\beta$-carotene, lycopene nor retinol was detected in seminal plasma or sperm from any groups [20]. But ascorbate and $\alpha$-tocopherol cooperate to protect lipid structures against peroxidation. Ascorbate recycles $\alpha$-tocopherol by repairing its tocopheroxyl radical [23].

Determination of antioxidant activity as an integral parameter provides more complete and valid information than the determination of individual antioxidants as it takes into account the cumulative effect of all antioxidants in the seminal fluid. The most frequently used methods are chemiluminescent and spectrophotometric ones [21,24]. The method of activated chemiluminescence is based on the ability of luminol to produce luminescence during its interaction with the radicals generated in the system. When added to the system of the test sample antioxidants contained therein start reacting with radicals and inhibit the chemiluminescence of phosphor.

The spectrophotometric method is based on the suppression of color by antioxidants, resulting from the generation of cation radical of 2,2'-azino-bis(3-ethylbenzothiazoline-6-sulphonic acid (ABTS ${ }^{\circ}$ ) [25]. Methods are including some stages and require standardization.

Despite a considerable quantity of the published data, the literature as a whole provides contradictory findings. Development of alternative analysis methods would be helpful in obtaining new results and resolving the contradictions.

Previously, we proposed a potentiometric method for determining antioxidan activity, which consists in measuring the potential shift in the mediator potassium ferricyanide/potassium ferrocyanide system $\mathrm{K}_{3}\left[\mathrm{Fe}(\mathrm{CN})_{6}\right] / \mathrm{K}_{4}\left[\mathrm{Fe}(\mathrm{CN})_{6}\right]$ [22] as a result of its interaction with antioxidants. The reliability of the results obtained by the potentiometric method is justified by comparative studies carried out with TAS Randox, independent certified spectrophotometric method [26]. The method was successfully used for the analysis of food products, food raw materials and dietary supplements [27], blood and its fractions [26], The method is also implemented as a non-invasive option [28].

The use of oxidized and reduced forms of the system and evaluation of their ratio in the measuring process as a source of information on antioxidant/oxidant activity of the sample gives the base to develop approach for determining antioxidant and oxidant activity in one analysis.

So, the aim of this study is development of the potentiometric method of semen antioxidant/oxidant activity evaluation in and the variant for doing it in one and the same measurement.

\section{EXPERIMENTAL}

\subsection{Instruments}

Potentiometric measurements were performed using a multipotentiometric analyzer MPA-1 (IVA, Ekaterinburg), and a pilot sample of potentiometric analyzer AOT-1 with RS232 interface (IVA, Ekaterinburg). A two-electrode electrochemical cell was used. Saturated silver/silver chloride electrode $\left(\mathrm{Ag} / \mathrm{AgCl} / 3 \mathrm{~mol} / \mathrm{dm}^{3} \mathrm{KCl}\right), \mathrm{EVL}-1 \mathrm{M}$ type (Gomel Measuring Equipment Plant, Gomel, Republic of Belarus) was used as referenceone. Platinum screen-printed electrode (IVA, Ekaterinburg) served as working electrode.

Sperm analysis was performed with automated analyzer MicrOptics (Spain) with the use of the automatic computer microvideography (CASA - computer-assisted semen analysis).

\subsection{Chemicals}

$\mathrm{K}_{4}\left[\mathrm{Fe}(\mathrm{CN})_{6}\right], \quad \mathrm{K}_{3}\left[\mathrm{Fe}\left(\mathrm{CN}_{6}\right)\right], \quad \mathrm{KH}_{2} \mathrm{PO}_{4}, \quad \mathrm{Na}_{2} \mathrm{HPO}_{4} \cdot 12 \mathrm{H}_{2} \mathrm{O}$, high purity grade were taken from Reakhim, Russia. Mixture of $\mathrm{K}_{3}\left[\mathrm{Fe}\left(\mathrm{CN}_{6}\right)\right]$ and $\mathrm{K}_{4}\left[\mathrm{Fe}(\mathrm{CN})_{6}\right]$ served as mediator system.

\subsection{Potentiometric Method for Determining Antioxidant Activity}

The potential shift of the Pt-electrode in the mediator system potassium ferricyanide/potassium ferrocyanide $\mathrm{K}_{3}\left[\mathrm{Fe}(\mathrm{CN})_{6}\right] / \mathrm{K}_{4}$ $\left[\mathrm{Fe}(\mathrm{CN})_{6}\right]$ which is observed after introduction of the seminal or follicular fluid sample to be analyzed into the solution 
$[22,26,27]$ provides information about antioxidant activity AOA of the biological fluid sample. This shift is a consequence of the changed ratio of oxidized and reduced forms of the mediator system components as a result of the following reaction:

$\mathrm{a} \cdot \mathrm{Fe}(\mathrm{III})+\mathrm{b} \cdot \mathrm{AO}=\mathrm{a} \cdot \mathrm{Fe}(\mathrm{II})+\mathrm{b} \cdot \mathrm{AO}_{\mathrm{Ox}}$

where $\mathrm{AO}$ - antioxidant; $\mathrm{AO}_{\mathrm{Ox}}$ - antioxidant oxidation product ; $\mathrm{a}, \mathrm{b}$ - stoichiometric coefficients of the reaction.

Antioxidant activity (M-eq) is calculated as follows (Eq. 2).

$A O A=\frac{C_{O x}-\alpha C_{\mathrm{Re} d}}{1+\alpha}$

where $\alpha=C_{O x} / C_{\operatorname{Re} d} \cdot 10^{\left(E_{1}-E\right) n F / 2.3 R T}$, and $E, E_{l}$ - potentials of the mediator system before and after interaction with the sample, $\mathrm{mV}$.

As the molecule of the antioxidant can include several functional groups with antioxidant properties, then antioxidant activity AOA is understood as effective equivalent concentration of antioxidants to react with $\mathrm{K}_{3}\left[\mathrm{Fe}(\mathrm{CN})_{6}\right]$, that is similar to the Trolox (i.e. 6-hydroxy-2,5,7,8tetramethylchroman-2-carboxylic acid) equivalent [25-26].

The potentiometric method can also be used to determine oxidant activity OA, which will be discussed below.

\subsection{Object of Analysis}

The study was performed with the samples of seminal fluid and seminal plasma obtained from 99 male patients, and with the samples of follicular fluid obtained from 27 female patients.

Quantitative and qualitative parameters of the ejaculate were evaluated:

- cells concentration;

- $\quad$ categories of spermatozoa mobility;

- $\quad$ speed of movement.

The parameters obtained were compared with physiological norms set by the World Health Organization. The ejaculate indicators were classified in accordance with the WHO guidelines [8]. Sperm analysis included cytology of gamete morphology in the colored smear preparations [8].

A fully diluted sample was used for the analysis of seminal fluid (native ejaculate). Dilution was determined by changing viscosity of semen, which was measured by the length of the 'thread' from the drop released from a syringe. The ejaculate was considered 'diluted' if the length of the 'thread' did not exceed $2 \mathrm{~cm}$. Dilution time was 20-40 $\min$ [27].

During the analysis of seminal plasma the native ejaculate was centrifuged (1500 rpm, $15 \mathrm{~min}$ ). Supernatant fluid was used.

Ejaculate of volunteers to whom diagnosis of oligo-, asteno, terato-, and the mixed forms of leykositospermie (study group) or normospermia (control group) was established have been included into researches.

Follicular fluid was centrifuged (2000 rpm, $20 \mathrm{~min}$ ) prior to the analysis in order to remove red blood and epithelial cells. Supernatant fluid was used in measurements.

\section{RESULT}

\subsection{Potentiometric Method for Determining Oxidant/ Antioxidant Activity}

In earlier studies [22] only AOA of whole blood, red blood cells, serum, and plasma were investigated. Possibility of oxidant activity (OA) detection follows from the data obtained in our previous work [29], where interaction of potassium ferrocyanide $\mathrm{K}_{4}\left[\mathrm{Fe}(\mathrm{CN})_{6}\right]$ with peroxyl radicals was studied.

Water-soluble azoinitiator 2,2'-azobis(2-amidinopropan)dihydrochloride (AAPH) was used as a source of peroxy radicals. During thermal exposure it decomposes as follows:

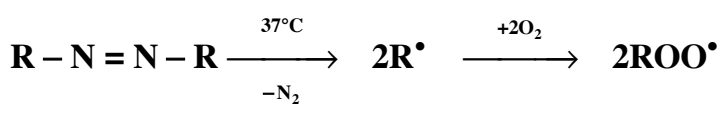

Fig. (1) shows increase of the potential over time during incubation of the mixture of AAPH and the mediator system $\left(37^{0} \mathrm{C}\right)$.

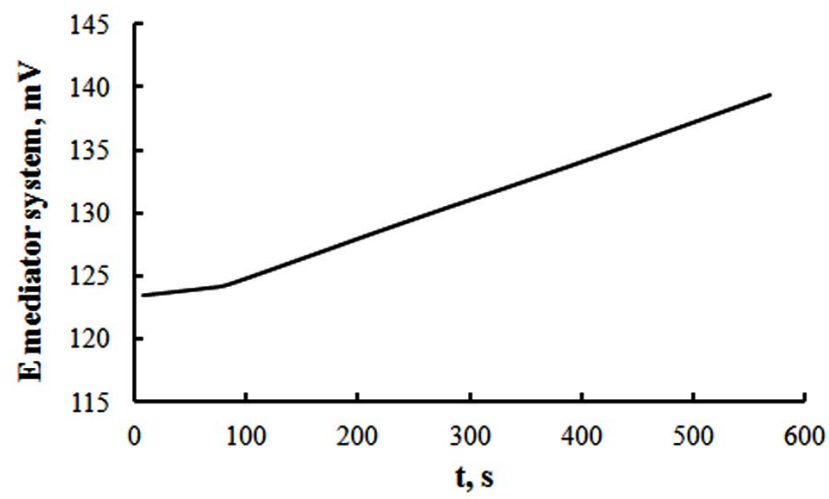

Fig. (1). Kinetic curves of ferricyanide $\mathrm{K}_{3}\left[\mathrm{Fe}(\mathrm{CN})_{6}\right]$ concentration increase at $37^{\circ} \mathrm{C}$ in the course of interaction of the ferricyanide/ferrocyanide mediator systems with peroxyl radicals produced by AAPH decomposition.

This increase is the consequence of oxidation of the reduced component of the ferricyanide/ferrocyanide mediator system by generated radicals.

The change of the potential of the ferricyanide/ferrocyanide mediator system during the study of the patient ejaculate having pathology of reproductive function is shown in Fig. (2).

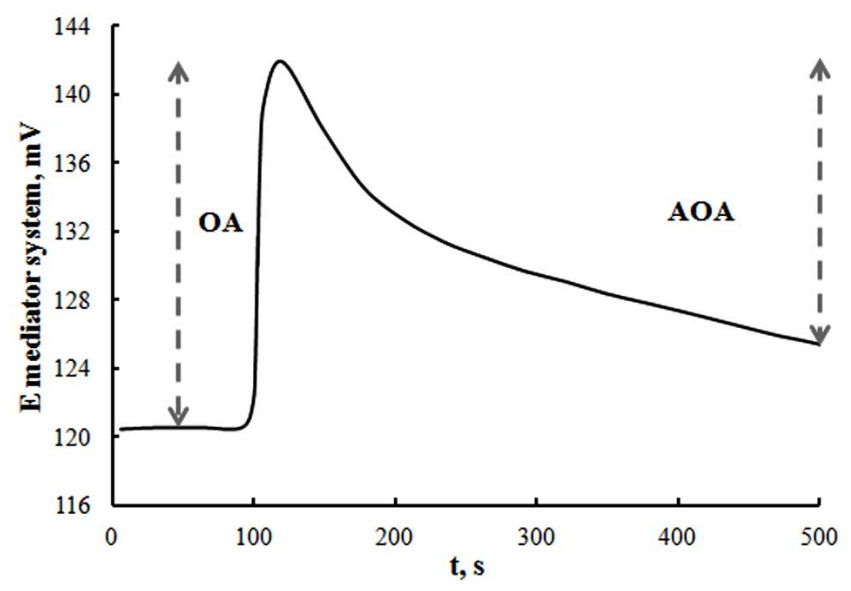

Fig. (2). Dependence of potential of ferricyanide/ferrocyanide mediator system on time for seminal fluid having oxidative activity. 


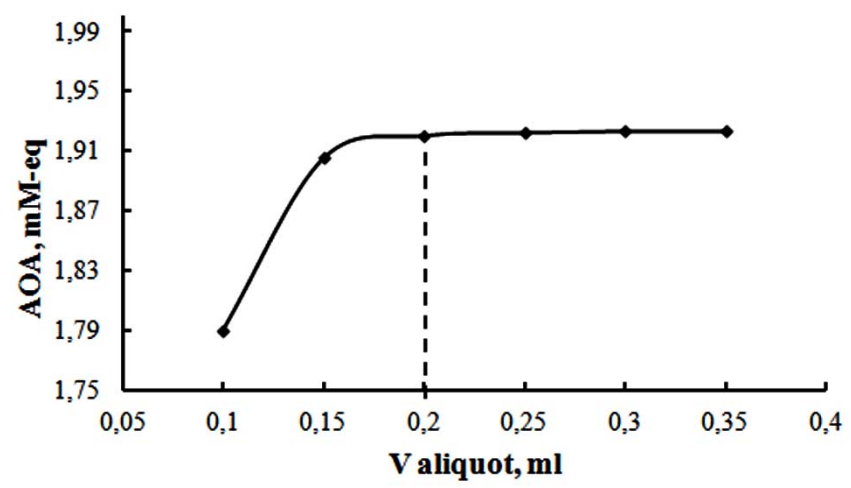

Fig. (3). Dependence of seminal liquid AOA determined by proposed potentiometric method after introduction of different seminal fluid sample volumes into the $1.0 \mathrm{~mL}$ solution in the cell.

An increase in the potential of the mediator system (from the initial one) is observed followed by a fall. This dependence of the potential shift of the ferricyanide/ferrocyanide mediator system over time is due to the interaction of oxidants with ferrocyanide $\mathrm{K}_{4}\left[\mathrm{Fe}(\mathrm{CN})_{6}\right]$ and subsequent interaction of antioxidants with ferricyanide $\mathrm{K}_{3}\left[\mathrm{Fe}(\mathrm{CN})_{6}\right]$. Obviously, the rate of reaction of the reduced component of the mediator system with free radicals and peroxide compounds (oxidants) is higher than the rate of reaction of the oxidized component of the mediator system with antioxidants of the sample. This enables evaluation of oxidant and antioxidant contribution to the antioxidant/oxidant state of the seminal fluid sample in one and the same experiment.

Contribution of the oxidant component can be estimated by measuring the change of the reduced component of the ferricyanide/ferrocyanide mediator system concentration due to oxidation (Reaction 2 ) after adding the sample

$\left[\mathrm{Fe}(\mathrm{CN})_{6}\right]^{4-}-\mathrm{e}^{-} \rightarrow\left[\mathrm{Fe}(\mathrm{CN})_{6}\right]^{3-}$

Oxidative activity (OA) can be calculated by Equation 3:

$O A=\frac{\alpha C_{\operatorname{Red}}-C_{O x}}{1+\alpha}$

where $\alpha=C_{O x} / C_{\mathrm{Red}} \cdot 10^{\left(E_{1}-E\right) n F / 2.3 R T}, E, E_{l}$ - potentials of the ferricyanide/ferrocyanide mediator system before and after interaction with the sample, $\mathrm{mV} ; \mathrm{C}_{\mathrm{Ox}}$ - concentration of the oxidized form of the ferricyanide/ferrocyanide mediator system in the cell, $\mathrm{M} ; \mathrm{C}_{\mathrm{Red}}$ - concentration of the reduced form of the ferricyanide/ferrocyanide mediator system in the cell, M; OA oxidant activity, mM-eq.

Thus, after interaction of mediator system with oxidants, concentrations of the oxidized and reduced components of ferricyanide/ferrocyanide mediator system can be expressed as follows:

$C_{O x}^{\prime}=C_{O x}+X$
$C_{\mathrm{Red}}^{\prime}=C_{\mathrm{Red}}-X$

where $\mathrm{X}$ - concentration of oxidants, $\mathrm{M}$-eq; $\mathrm{C}_{\mathrm{OX}}^{\prime}$ - concentration of the oxidized form of the ferricyanide/ferrocyanide mediator system in the cell after interaction with oxidants, $\mathrm{M} ; \mathrm{C}_{\text {Red }}^{\prime}-$ concentration of the reduced form of the ferricyanide/ferrocyanide mediator system in the cell after interaction with oxidants.

Then, taking into account the steady-state concentrations of the components of the mediator system, antioxidant activity AOA can be calculated using Eq. 6, 7:

$$
\begin{aligned}
& A O A=\frac{C_{O x}^{\prime}-\alpha C_{\mathrm{Re} d}^{\prime}}{1+\alpha} \\
& \alpha=C_{O x}^{\prime} / C_{\mathrm{Red}}^{\prime} \cdot 10^{\left(E_{1}^{\prime}-E^{\prime}\right) n F / 2.3 R T}
\end{aligned}
$$

where $\mathrm{E}^{\prime}$ - potential of the ferricyanide/ferrocyanide mediator system after interaction with oxidants, $E_{1}^{\prime}$ - potential of the ferricyanide/ferrocyanide mediator system after interaction with oxidants and antioxidants.

\subsection{Research and the Analysis of Seminal and Follicular Liquids}

AOA of a seminal liquid in samples without oxidant activity lie in the range from 0,65 to $2,90 \mathrm{mM}$-eq. Using ferricyanide/ferrocyanide mediator system containing $0,01 \mathrm{M} \mathrm{K}_{3}$ $\left[\mathrm{Fe}(\mathrm{CN})_{6}\right]$ and $0.0001 \mathrm{MK}_{4}\left[\mathrm{Fe}(\mathrm{CN})_{6}\right]$ provides the possibility to obtain shift of potential about $20-60 \mathrm{mV}$.

The value of AOA of a follicular liquid (fluid) corresponds to the AOA value of blood plasma. Taking into account these conditions and previously published data [22] we have chosen ferricyanide/ferrocyanide mediator system containing $0,001 \mathrm{M}$ $\mathrm{K}_{3}\left[\mathrm{Fe}(\mathrm{CN})_{6}\right]$ and $0,00005 \mathrm{M} \mathrm{K}_{4}\left[\mathrm{Fe}(\mathrm{CN})_{6}\right]$ for determination of a follicular liquid AOA.

Fig. (3) shows dependence of AOA found in seminal fluid from sample volume introduced into the cell.

Bearing in mind these data and limited quantity of the seminal and follicular fluid samples we've chosen for the analysis the conditions given in the Table 1 .

Comparative results obtained for AOA of a seminal fluid (native ejaculate) and seminal plasma are presented on Fig. (4). It is seen, that AOA of native ejaculate is almost identical or slightly exceeds the seminal plasma AOA. It is due to the fact, that native ejaculate on $95 \%$ consists of seminal plasma.

The data presented give the base to exclude a stage of centrifugation and to analyze native seminal liquid.

Fig. (5) demonstrates antioxidant activity found in analysis of fresh ejaculate (directly after delivery, its dilution and storage 30 mines), and after dilution and the further freezing $\left(-18^{0} \mathrm{C}\right)$. Obtained data practically coincides.

Table 1. Conditions for Analysis of Seminal and Follicular Fluids

\begin{tabular}{|c|c|c|c|c|}
\hline $\begin{array}{c}\text { Fluid to be } \\
\text { Analyzed }\end{array}$ & $\begin{array}{c}\text { Mediator System } \mathbf{C}_{\mathbf{o x}} / \mathbf{C}_{\mathbf{R e d}}, \\
\mathbf{M} / \mathbf{M}\end{array}$ & $\begin{array}{c}\text { Buffer Solution } \\
\text { Volume, } \mathbf{m l}\end{array}$ & $\begin{array}{c}\text { Volume of the Sample } \\
\text { Introduced into the Cell, } \mathbf{m l}\end{array}$ & $\begin{array}{c}\text { Dilution of the } \\
\text { Sample }\end{array}$ \\
\hline \hline Seminal liquid & $10^{-2} / 10^{-4}$ & 1 & 0,2 & 6 \\
\hline Follicular liquid & $10^{-3} / 5 \cdot 10^{-5}$ & 1 & 0,2 & 6 \\
\hline
\end{tabular}




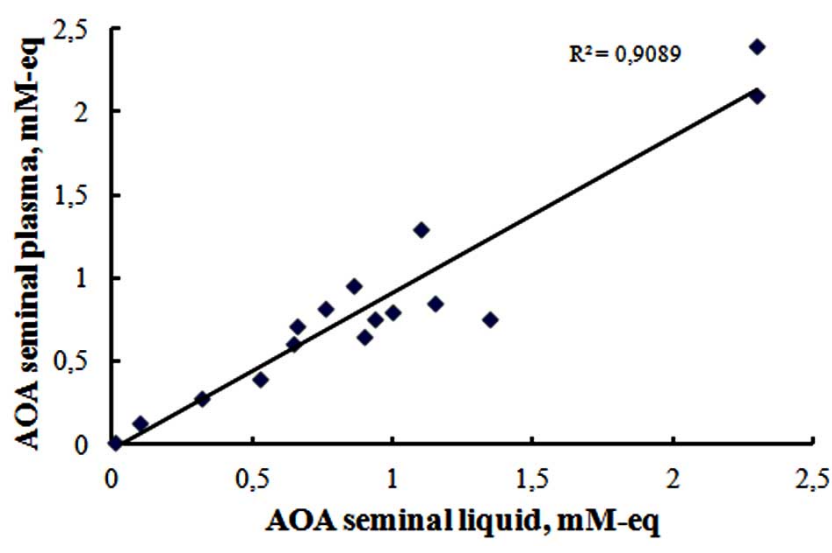

Fig. (4). The correlation between the results of AOA seminal liquid and AOA seminal plasma.

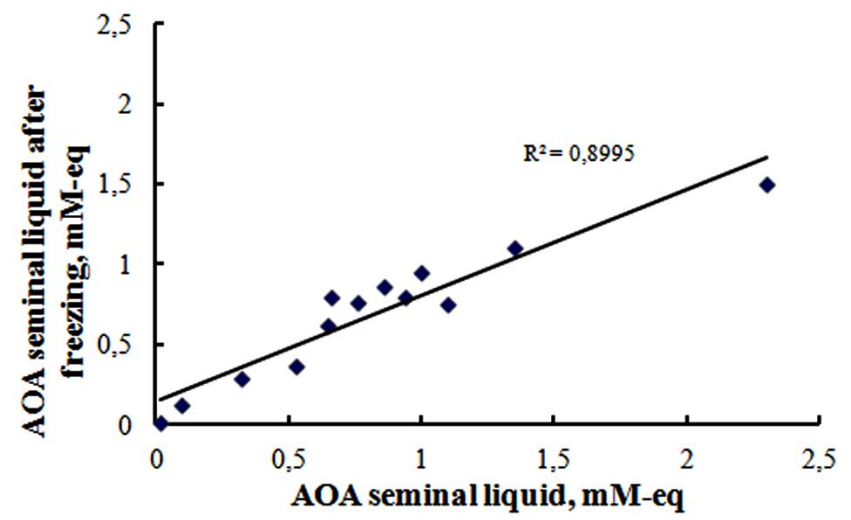

Fig. (5). The correlation between the results of found AOA seminal liquid before and after freezing.

Also high correlation $\left(R^{2}=0,9336\right)$ of results of AOA seminal plasma before and after freezing is observed, that permits to use both fresh, or preliminary frozen seminal and follicular fluid samples for the proposed potentiometric analysis.

AOA of the follicular liquid obtained from different follicles of the same patient is given in Table 2 .

Table 2. AOA of a Follicular Liquid of the First and the Second Follicules $(\mathbf{n}=\mathbf{3}, \mathbf{P}=\mathbf{0 , 9 5})$

\begin{tabular}{|c|c|c|c|c|}
\hline \multirow{2}{*}{ №. } & \multicolumn{4}{|c|}{ AOA, MM-eq } \\
\cline { 2 - 5 } & First Follicle & $\mathbf{S}_{\mathbf{r}}$ & Second Follicle & $\mathbf{S}_{\mathbf{r}}$ \\
\hline \hline 1 & $0,99 \pm 0,04$ & 0,02 & $1,03 \pm 0,07$ & 0,03 \\
\hline 2 & $1,10 \pm 0,06$ & 0,03 & $0,98 \pm 0,06$ & 0,03 \\
\hline 3 & $0,97 \pm 0,07$ & 0,03 & $0,95 \pm 0,05$ & 0,02 \\
\hline 4 & $1,11 \pm 0,09$ & 0,04 & $0,96 \pm 0,06$ & 0,03 \\
\hline 5 & $0,77 \pm 0,05$ & 0,03 & $0,73 \pm 0,03$ & 0,02 \\
\hline
\end{tabular}

There is no significant difference between AOA of two samples. Thus, a follicular liquid from only one follicle can be used for investigation of interelation between antioxidant activity, fertilisation and development of embryos.

The drawback of this approach is necessity of surgical procedure to obtain the sample for investigation. It would be much better if the same inforamation could be obtained from blood analysis. Fortunately, quite good correlation (76 \%) of these parameters is observed, that is seen from Fig. (6).

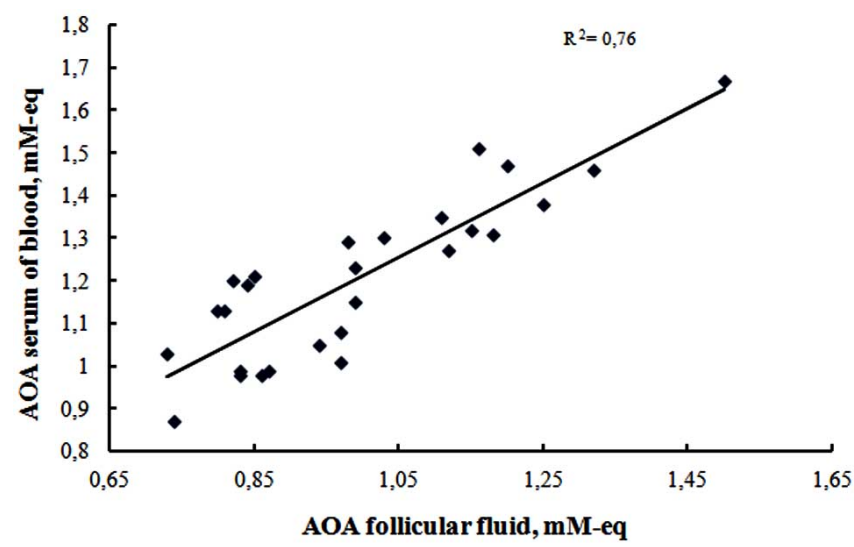

Fig. (6). The correlation between the results of AOA follicular liquid and AOA serum of blood.

\subsection{OA/AOA of a Seminal Liquid at Various Kinds of Pathology of Reproductive Function}

AOA and OA of ejaculate obtained from oligo-, asteno-, terato- and the mixed forms pathospermia (study group) and normospermia (control group) patients are presented on the diagram.

Antioxidant activity of ejaculate in groups where various kinds of pathology were found slightly lower than in normospermie group. It is in general agreement with results of other researches [2, 4, 30-31]. Oxidant activity (negative magnitudes on the Fig. 7) in the both groups where the various kinds of pathology were found have been determined by proposed method.

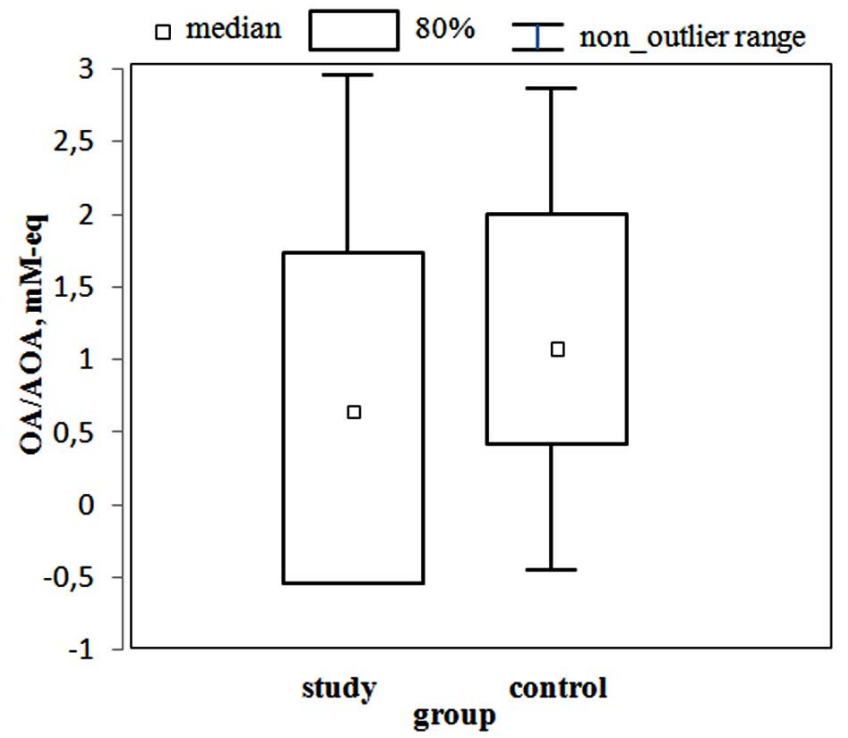

Fig. (7). Oxidant/antioxidant activity of seminal liquid in the control group (normospermia, 27 subjects) and study group (pathospermia, 72 subjects).

Ratios between quantity of ejaculate samples obtained from oligo-, asteno-, terato- and the mixed forms pathospermia and normospermia patients in what oxidant activity was found and 
samples in what oxidant activity was not found are presented in the Table 3 .

Table 3. Distribution Samples in which Oxidant Activity is Found

\begin{tabular}{|c|c|c|}
\hline Diagnosis & $\begin{array}{c}\text { Samples with } \\
\text { Oxidant Activity (\%) }\end{array}$ & $\begin{array}{c}\text { Samples without } \\
\text { Oxidant Activity (\%) }\end{array}$ \\
\hline \hline $\begin{array}{c}\text { Normospermia } \\
\text { (27 patients) }\end{array}$ & 11,1 & 88,9 \\
\hline $\begin{array}{c}\text { Pathospermia } \\
\text { (72 patients) }\end{array}$ & 40,3 & 59,7 \\
\hline
\end{tabular}

The obtained data correspond to the published results [31] in spite of the fact that principally different analysis methods were used.

\section{DISCUSSION}

Unfortunately, the available literature data provides contradictory findings in the interrelationship between antioxidant/oxidant activity of semen fluid and human reproductive function. There is no consensus on the reference total antioxidant activity of seminal plasma in healthy fertile men. Data spread is observed in the range from $1.21 \pm 0.16$ to 2.32 $\pm 033 \mathrm{mmol} / \mathrm{L}$ [2]. Our data are positioned in the same range, but it is too wide to do any conclusion. In described here studies the values of semen plasma AOA in the group of men where pathology was found were not significantly different form the control group ( $2.15 \pm 0.29$ versus $2.32 \pm 0.33 \mathrm{mM}$-eq, $p>0.05)$.

It is important, that oxidant activity $\mathrm{OA}$ is observed in pathology conditions and when infertility appearing. Data given in the Table 3 clearly defined it. Thiele et al., [20] suggested that ROS activity detected in the group of infertile men is due to an increase in the ROS generation rather than as consequence of decreased ROS scavenging. So, the decrease of antioxidant activity AOA is not displayed noticeably. Nevertheless, a significant decrease in antioxidant activity AOA of seminal plasma of infertile patients compared with that of fertile men was observed. Obviously, oxidant/antioxidant status appears to be one of the most important factors in the men infertility.

\section{CONCLUSIONS}

Two main conclusions should be done taking into account the all above mentioned data:

- It is necessary to carry out wide investigations of patients, divided at least in two groups: fertile and infertile men;

- To develop additional/alternative methods that would be designed to provide information on antioxidant and oxidant activity of semen and follicular fluids.

We need no time consuming, easy to use, cost effective methods for determination of oxidant/antioxidant status of seminal fluids to fit these goals. Proposed here potentiometric method, described in our paper, in some degree leading to solve these problems.

Essential advantage of the proposed here potentiometric method is the simultaneous use of two forms of the ferricyanide/ferrocyanide mediator system (oxidized and reduced ones) that allows estimating oxidant and antioxidant components of the seminal or follicular fluid sample. It is natural to believe that oxidant activity OA of a seminal liquid is caused by presence of oxygen radicals and peroxides, both organic, and inorganic nature which react with the reduced component of the ferricyanide/ferrocyanide mediator system and oxidizing it. This process leads to the shift of the measured electrode potential that is a source of information on concentration ROS in the seminal or follicular fluid sample. Estimation possibility of the oxidant and antioxidant activity in the single measurement is looking essential to the prediction and diagnostics of man's infertility pathogenesis and its efficient therapies.

\section{ACKNOWLEDGEMENT}

Declared none.

\section{CONFLICT OF INTEREST}

Declared none.

\section{REFERENCES}

[1] De Jonge, C.J.; Barratt, C.L.R. The sperm cells: production, maturation, fertilization, regeneration, Cambridge University Press: UK, Cambridge, 2006.

[2] Fingerova, H.; Novotny, J.; Barborik, J.; Brezinova, J.; Svobodova, M.; Krskova, M.; Oborna, I. Antioxidant capacity of seminal plasma measured by TAS Randox. Biomed. Pap. Med. Fac. Univ. Palacky Olomouc Czech Repub., 2007, 151, 37.

[3] Cocuzza, M.; Sikka, S.C.; Athayde, K.S.; Agarwal, A. Clinical relevance of oxidative stress and sperm chromatin damage in male infertility: an evidence based analysis. Int. Braz. J. Urol., 2007, 33, 603.

[4] Yadav, S.B.; Suryakar, A.N.; Huddedar, A.D.; Shukla, P.S. Effect of antioxidants and antibiotics on levels of seminal oxidative stress in leukocytospermic infertile men. Indian J. Clin. Biochem., 2006, 21,152 .

[5] Pasqualotto, F.F.; Pasqualotto, E.B. Reactive oxygen species and oocyte fertilization. Hum. Reprod., 2007, 22, 901.

[6] Jancar, N.; Kopitar, A.; Ihan, A.; Klun, I.; Bokal, E. Effect of apoptosis and reactive oxygen species production in human granulosa cells on oocyte fertilization and blastocyst development. J. Assist. Reprod. Genet., 2007, 24, 91.

[7] Goud, A.P.; Goud, P.T.; Diamond, M.P.; Gonik, B.; Abu-Sou, H.M. Reactive oxygen species and oocyte aging: role of superoxide, hydrogen peroxide, and hypochlorous acid. Free Radic. Biol. Med., 2008, 44, 1295.

[8] World Health Organization, Department of Reproductive Health and Research. WHO laboratory manual for the examination and processing of human semen, 5th ed., Department of Reproductive Health and Research, 2010.

[9] Esfandiari, N.; Sharma, R.K.; Saleh, R.A.; Thomas, A.J.; Agarwal, A. Utility of the nitroblue tetrazolium reduction test for assessment of reactive oxygen species production by seminal leukocytes and spermatozoa. J. Androl., 2003, 24, 862.

[10] Guthrie H.D.; Welch, G.R. Determination of intracellular reactive oxygen species and high mitochondrial membrane potential in Percoll-treated viable boar sperm using fluorescence-activated flow cytometry. J. Anim. Sci., 2006, 84, 2089.

[11] Valgimigli, L.; Pedulli, G.F.; Paolini, M. Measurement of oxidative stress by EPR radical-probe technique. Free Radic. Biol. Med., 2001, 31, 708 .

[12] Rajasekaran, M.; Hellstrom, W.J.; Naz, R.K.; Sikka, C.S. Oxidative stress and interleukins in seminal plasma during leukocytospermia. Fertil. Steril., 1995, 64, 166.

[13] Buch, J.P.; Kolon, T.F.; Maulik, N.; Kreutzer, D.L.; Daz, D.K. Cytokines stimulate lipid membrane peroxidation of human sperm. Fertil. Steril., 1994, 62, 186.

[14] Laudata, A.; Lecourbe, K.; Guechot, J.; Palluel, A-M. Values of sperm thiobarbituric acid-reactive substance in fertile men. Clin. Chim. Acta, 2002, 325, 113.

[15] Aitken, R.J.; Baker, M.A.; Sawyer, D. Oxidative stress in the male germ line and its role in the aetiology of male infertility and genetic disease. Reprod. Biomed. Online, 2003, 7, 65 
[16] Aitken, R.J.; Baker, M.A. Oxidative stress and male reproductive biology. Reprod. Fertil. Dev., 2004, 16, 581.

[17] Kmenta, I.; Strohmayer, C.; Muller-Schlosser, F.; Schafer-Somi, S. Effects of a lecithin and catalase containing semen extender and a second dilution with different enhancing buffers on the quality of cold-stored canine spermatozoa. Theriogenology, 2011, 75, 1095.

[18] Abd-Elmoaty, M.A.; Saleh, R.; Sharma. R.; Agarwal, A. Increased levels of oxidants and reduced antioxidants in semen of infertile men with varicocele. Fertil. Steril., 2010, 94, 1531.

[19] Lewis, S.E.; Sterling, E.S.; Young, I.S.; Thompson, W. Comparison of individual antioxidants of sperm and seminal plasma in fertile and infertile men. Fertil. Steril., 1997, 67, 142.

[20] Thiele, J.J.; Friesleben, H.J.; Fuchs, J.; Ochsendorf, F.R. Ascorbic acid and urate in human seminal plasma: determination and interrelationships with chemiluminescence in washed semen. Hum. Reprod., 1995, 10, 110.

[21] Said, T.M.; Kattal, N.; Sharma, R.K. Enhanced chemiluminescence assay $v s$ colorimetric assay for measurement of the total antioxidant capacity of human seminal plasma. J. Androl., 2003, 24, 676.

[22] Brainina, Kh.Z.; Alyoshina, L.V.; Gerasimova, E.L.; Kazakov, Ya.E.; Ivanora, A.V.; Beykin, Ya.B.; Belyaera, S.Y.; Usatora, T.I.; Khodos, M.Ya. New electrochemical method of determining blood and blood fractions antioxidant activity. Electroanalysis, 2009, 21, 618.

[23] Buettner, G. R. The pecking order of free radicals and antioxidants: lipid peroxidation, alpha-tocopherol, and ascorbate. Arch. Biochem. Biophys., 1993, 300, 535.

[24] Sharma, R.K.; Pasqualotto, F.F.; Nelson, D.R., Thomas, A.J.; Agarwal, A. The reactive oxygen species-total antioxidant capacity score is a new measure of oxidative stress to predict male infertility. Hum. Reprod., 1999, 14, 2801.

[25] Miller, N.J.; Rice-Evans, C.A. Factors influencing the antioxidant activity determined by the ABTS.+ radical cation assay. Free Radic. Res., 1997, 26, 195.

[26] Brainina, Kh.Z.; Kositzina, A.N.; Ivanova, A.V. Comprehensive analytical chemistry. Electrochemical sensor analysis: Screen printed enzyme-free electrochemical sensors for clinical and food analysis, Ed. D. Barcelo; Elsevier : Amsterdam, 2007; Vol. 49. pp. 643-666.

[27] Brainina, Kh.Z.; Ivanova, A.V.; Sharafutdinova, E.N.; Lozovskaya, E.L.; Shkarina E. Potentiometry as a method of antioxidant activity investigation. Talanta, 2007, 71, 13.

[28] Brainina, K.; Galperin, L.; Gerasimova, E.; Khodos, M. Noninvasive Potentiometric Method of Determination of Skin Oxidant/Antioxidant Activity. IEEE Sens. J., 2011, doi:10.1109/JS EN.2010.2100040.

[29] Brainina, Kh.Z.; Gerasimova, E.L.; Kasaikina, O.T.; Ivanova A.V. Antooxidant activity evaluation assay based on peroxide radicals generation and potentiometric measurement. Anal. Lett., 2011, 44, 1405.

[30] Yadav, S.B.; Suryakar, A.N.; Huddedar, Durgawale, P.P.; A.D.; Shukla, P.S. Antioxidant treatment a new therapeutic approach to reversible male interfility. Biomed. Res., 2006, 17, 175.

[31] Novotny, J.; Oborna, I.; Brezinova, J.; Svobodova, M.; Hrbac, J.; Fingerova, $H$. The occurrence of reactive oxygen species in the semen of males from infertile couples. Biomed. Pap. Med. Fac. Univ. Palacky Olomouc Czech Repub., 2003, 147, 173.

(C) Brainina et al.; Licensee Bentham Open.

This is an open access article licensed under the terms of the Creative Commons Attribution Non-Commercial License (http://creativecommons.org/licenses/by$\mathrm{nc} / 3.0 /$ ) which permits unrestricted, non-commercial use, distribution and reproduction in any medium, provided the work is properly cited. 